\title{
A visão utópica da CEPAL e a desigualdade de renda no Brasil
}

ECLAC's Utopian Vision and Income Inequality in Brazil

La vision utopique de la CEPALC et l'inégalité des revenus au Brésil

Fernando Augusto Mansor de Mattos, João Hallak Neto e Marcelo

Weishaupt Proni

\section{OpenEdition}

\section{Journals}

Edição electrónica

URL: https://journals.openedition.org/rccs/11605

DOI: $10.4000 /$ rccs. 11605

ISSN: $2182-7435$

\section{Editora}

Centro de Estudos Sociais da Universidade de Coimbra

\section{Edição impressa}

Data de publição: 1 maio 2021

Paginação: 131-156

ISSN: 0254-1106

\section{Refêrencia eletrónica}

Fernando Augusto Mansor de Mattos, João Hallak Neto e Marcelo Weishaupt Proni, «A visão utópica da CEPAL e a desigualdade de renda no Brasil», Revista Crítica de Ciências Sociais [Online], 124 | 2021, publicado a 26 maio 2021, consultado a 28 maio 2021. URL: http://journals.openedition.org/rccs/ 11605 ; DOI: https://doi.org/10.4000/rccs.11605 


\section{FERNANDO AUGUSTO MANSOR DE MATTOS, JOÃO HALLAK NETO, MARCELO WEISHAUPT PRONI}

\section{A visão utópica da CEPAL e a desigualdade de renda no Brasil}

Em 2014, a Comissão Econômica para a América Latina e o Caribe (CEPAL) afirmava que uma estratégia de desenvolvimento direcionada para maior equidade econômica, maior justiça social e maior proteção ambiental poderia ser adotada em vários países da América Latina - um cenário que, no entanto, se desfigurou nos últimos anos. Este artigo tem assim três objetivos: (1) analisar o caráter utópico da agenda da CEPAL para a promoção de sociedades mais igualitárias na América Latina; (2) elencar os principais determinantes da redução da desigualdade de renda no Brasil no período 2004-2014; e (3) examinar a interrupção da trajetória de redução da desigualdade de renda - a partir do golpe político de 2016 e da aprovação de reformas neoliberais que aumentaram a precariedade dos empregos e enfraqueceram o sistema de proteção social -, como evidência da interdição de uma estratégia de desenvolvimento inclusivo no Brasil.

Palavras-chave: América Latina; Brasil; CEPAL; desigualdades laborais; mercado de trabalho.

Pobreza em meio à abundância não reflete alguma lei inalterável da natureza; ela é o resultado do caminho existente de organizações sociais de poder e desigualdade que afetam massivamente as possibilidades de florescimento humano. [...] A utopia em "utopia real" significa pensar sobre alternativas para instituições dominantes no sentido de incorporar nossas mais profundas aspirações para um mundo justo e humano.

WRIGHT (2011: 3)

\section{Introdução}

Nos primeiros 15 anos do século XXI, a maioria dos países da América Latina apresentou expressiva redução da desigualdade econômica, 
nomeadamente quando medida pela renda do trabalho. ${ }^{1}$ Ainda assim, a América Latina continuou a reunir alguns países com elevadíssimo grau de concentração de renda. As razões da redução gradual da desigualdade e as dificuldades no enfrentamento de suas causas foram objeto de interpretações econômicas e sociológicas.

Estudos publicados pela Comissão Econômica para a América Latina e o Caribe (CEPAL) ${ }^{2}$ no início da década de 2010 (CEPAL, 2010, 2012a, 2014) enfatizaram que a promoção da igualdade deveria assumir centralidade na agenda pública. $\mathrm{O}$ crescimento econômico e os programas sociais estavam a contribuir para a redução da pobreza na região, mas era necessário combater as causas estruturais e institucionais da desigualdade e transitar para um estilo de desenvolvimento sustentável. Porém, a partir de meados dessa década, a conjuntura mudou e o número de pessoas abaixo da linha de pobreza aumentou. Diante do novo cenário, a desigualdade de renda na América Latina seguiu diferentes trajetórias: entre 2014 e 2019, o índice de Gini continuou a se reduzir em alguns países (Bolívia, México e Paraguai), se manteve estável em outros (Chile, Uruguai) e aumentou no Brasil e Argentina (CEPAL, 2021: 66). A elevada desigualdade foi compreendida não apenas como uma questão ética, mas sobretudo como um problema econômico, uma vez que dificulta ganhos de produtividade e prejudica a eficiência dos mercados (CEPAL, 2018).

O enfoque cepalino se diferencia de outras abordagens porque vai além do crescimento econômico com redução da pobreza, uma vez que prioriza o combate às desigualdades econômicas e defende uma estratégia nacional de desenvolvimento multidimensional e integrado. ${ }^{3}$ A CEPAL tem diagnosticado os obstáculos centrais e identificado um conjunto de políticas e reformas econômicas capazes de avaliar as diferentes formas de manifestação de desigualdades. Este enfoque combina, portanto, um ideal de transformação social com uma análise empírica da realidade latino-americana, situando-se num meio termo entre idealismo e pragmatismo. Segundo Cordera Campos (2014), tais proposições são fundamentadas na crença de que é possível

\footnotetext{
${ }^{1}$ Neste artigo é ilustrado apenas o aspecto econômico da desigualdade, mas não perdemos de vista que, sob o capitalismo, as desigualdades geradas estendem-se para além da renda e da riqueza. Dedecca (2012) chama também a atenção para a necessidade de discutir a desigualdade segundo um ponto de vista multidimensional.

${ }^{2}$ Criada em 1948, a CEPAL é uma das cinco comissões regionais da Organização das Nações Unidas que tem como mandato o estudo e a promoção de políticas para o desenvolvimento de sua região. Funciona como um centro de excelência de altos estudos, que contribui para o debate da economia e da sociedade latino-americana e caribenha, apresentando diagnósticos, ideias e propostas de políticas públicas.

${ }^{3}$ Nesse sentido, é bem mais ambiciosa do que a estratégia de combate à pobreza extrema e à desigualdade de renda recomendada pelo Banco Mundial (The World Bank, 2016).
} 
implantar um projeto político de transformação econômica e social, pautado nas ideias de justiça e democracia, e assim converter o desenvolvimento nacional em uma "utopia realista".

A conjuntura internacional e os contextos domésticos possibilitaram a formulação de "utopias realistas" em países da América Latina, que pareciam viáveis no início da década de 2010, mas sofreram intenso ataque diante da virada neoliberal que assolou a maioria dos governos daquele território. Foi abortada a construção ideológica de modos de desenvolvimento inclusivo no continente latino-americano, principalmente em razão da histórica fragilidade da democracia na região. Por outro lado, a adoção de políticas e reformas neoliberais foi motivo de movimentos de contestação em vários países (Chile, Argentina e outros mais). Por isso, a América Latina pode ser considerada um laboratório de vívido interesse para investigações de questões ligadas à desigualdade, em suas diversas dimensões, as quais remetem para um debate acerca do papel das instituições que conformam a democracia nos países do continente.

As distintas experiências de desenvolvimento nacional na América Latina, nas duas primeiras décadas do século XXI, sugerem existir uma grande distância entre o discurso e a prática. No caso do Brasil, em particular, houve progresso visível na redução da desigualdade (e da pobreza) entre 2004 e 2014, fenómeno característico do que o Banco Mundial e a Organização para a Cooperação e Desenvolvimento Econômico (OCDE) chamaram de "crescimento inclusivo" (Mello e Dutz, 2012). Mas, desde 2015, quando a economia entrou em recessão e eclodiu uma crise política, o discurso da inclusão social foi esvaziado em meio à deterioração do mercado de trabalho e ao desmonte de políticas sociais, o que causou impacto negativo imediato no perfil distributivo e nas condições de vida da população.

Este artigo tem três objetivos: (1) analisar o caráter utópico da agenda da CEPAL para a promoção de sociedades mais igualitárias na América Latina; (2) elencar os principais determinantes da redução da desigualdade de renda no Brasil no período 2004-2014; e (3) examinar a interrupção dessa trajetória de redução da desigualdade de renda como evidência da interdição de uma estratégia de desenvolvimento inclusivo no Brasil.

$\mathrm{O}$ artigo está assim dividido em três seções (além desta introdução e das considerações finais). Na primeira, procura-se compreender o enfoque da CEPAL para explicar a importância do combate à desigualdade econômica na agenda do desenvolvimento sustentável na América Latina, destacando também o caráter multidimensional requerido para melhorar a qualidade de vida da população. $\mathrm{Na}$ segunda, busca-se compreender a evolução recente da distribuição de renda no Brasil, procurando ressaltar que os 
desdobramentos da crise econômica sobre o mercado de trabalho nacional fizeram a desigualdade voltar a aumentar. $\mathrm{Na}$ terceira seção, argumenta-se que a ruptura política que tirou do poder a Presidente Dilma Rousseff significou a interdição do processo de inclusão social, ressaltando-se o aumento do desemprego e de ocupações precárias e a estagnação dos rendimentos (não é analisada a restrição de gastos com políticas sociais).

Ao longo do texto são elencadas algumas importantes mudanças institucionais que devem ser contempladas para que países latino-americanos retomem a trajetória de redução das desigualdades econômicas. É ressaltada a necessidade de adotar uma estratégia na qual as políticas sociais ajudem a promover um desenvolvimento inclusivo. Ademais, são considerados aspectos da recente dinâmica política no Brasil, que ora favoreceram ora bloquearam a construção de "utopias reais" (Wright, 2010).

\section{A agenda da CEPAL e a desigualdade econômica na América Latina}

A desigualdade econômica na América Latina é uma questão antiga. Diversos estudos importantes procuraram compreender as raízes históricas dessa desigualdade, reconhecendo que o problema vem desde a época colonial (Frankema, 2009; Sokoloff e Robinson, 2004) ou, pelo menos, desde os processos de independência (Bértola e Ocampo, 2015). Há também estudos que procuram se ater ao último século (Bértola et al., 2009) ou que incluem uma comparação histórica longa com outros continentes (Bourguignon e Morrisson, 2002; Gasparini, 2006), sempre destacando o caráter crônico da desigualdade nos países latino-americanos.

A evolução da desigualdade de renda na América Latina medida pelo índice de Gini revela que alguns países do continente estão entre os mais desiguais do mundo (The World Bank, 2016). A média do índice para o conjunto dos países latino-americanos tem se mantido acima das respectivas médias para a África, a Ásia, o Leste da Europa e os países economicamente mais avançados. Nas décadas de 1980 e 1990, a desigualdade subiu significativamente em todos os continentes, exceto em África. Na primeira década do século XXI, porém, houve redução da desigualdade de renda em muitos países, em especial na América Latina.

O índice de Gini da América Latina (média simples de 18 países) caiu de 0,54 para 0,49 entre 2002 e 2008, depois para 0,46 em 2019 (CEPAL, 2021: 66). Nesse mesmo ano, os níveis de desigualdade no Brasil $(0,54)$ e na Colômbia $(0,53)$ persistiam entre os mais altos do mundo, enquanto Argentina $(0,40)$ e Uruguai $(0,39)$ apresentavam os menores níveis na região (Tabela 1$)$.

Na primeira metade da década de 2010 o crescimento econômico desacelerou na região. Desde 2015, a queda dos preços internacionais das 
commodities agrícolas e minerais (com efeitos nefastos sobre muitas economias da região) e a adoção de políticas econômicas de austeridade fiscal provocaram aumento da pobreza e, em alguns casos, elevação da desigualdade de renda.

TABELA 1 - Índice de Gini do rendimento das pessoas de 12 países selecionados na América Latina (2002-2019)

\begin{tabular}{cccccc}
\hline País & $\mathbf{2 0 0 2}$ & $\mathbf{2 0 0 8}$ & $\mathbf{2 0 1 4}$ & $\mathbf{2 0 1 7}$ & $\mathbf{2 0 1 9}$ \\
\hline Argentina & 0,498 & 0,413 & 0,391 & 0,388 & 0,400 \\
\hline Bolívia & 0,612 & 0,513 & 0,471 & 0,461 & 0,430 \\
\hline Brasil (a) & 0,570 & 0,536 & 0,514 & 0,533 & 0,538 \\
\hline Chile (b) & 0,507 & 0,478 & 0,466 & 0,454 & $-\cdots$ \\
\hline Colômbia (c) & 0,567 & 0,572 & 0,540 & 0,511 & 0,529 \\
\hline Costa Rica (c) & 0,497 & 0,491 & 0,498 & 0,496 & 0,495 \\
\hline Equador & 0,538 & 0,496 & 0,449 & 0,444 & 0,456 \\
\hline México (d) & 0,506 & 0,513 & 0,502 & 0,491 & 0,464 \\
\hline Paraguai & 0,584 & 0,516 & 0,522 & 0,503 & 0,473 \\
\hline Peru & 0,544 & 0,495 & 0,446 & 0,448 & 0,429 \\
\hline Uruguai & 0,474 & 0,453 & 0,392 & 0,390 & 0,392 \\
\hline Venezuela & 0,418 & 0,379 & 0,378 & --- & --- \\
\hline $\begin{array}{c}\text { América Latina } \\
\text { (12 países) }\end{array}$ & 0,526 & 0,488 & 0,464 & 0,465 & 0,461 \\
\hline
\end{tabular}

Fonte: Elaboração própria a partir de CEPAL (2021: Quadro I.A2.3, pp. 85-87).

Notas: (a) os índices para 2017 e 2019 não são comparáveis com os de anos anteriores; (b) índices referentes a 2003, 2009, 2013 e 2017; (c) os índices para 2002 e 2008 não são comparáveis com os de anos posteriores; (d) índices referentes a 2016 e 2018 não são comparáveis com os de anos anteriores.

A nova agenda cepalina reforçou o compromisso com a promoção da igualdade econômica na América Latina, tendo como base o enfoque neoestruturalista, que prioriza a análise da dinâmica das estruturas produtivas e sociais e o ambiente institucional numa perspectiva histórica. Embora a desigualdade tenha sido um tema importante desde sua fundação (em 1948), a questão assumiu centralidade na década de 2010 com a publicação de três relatórios que viriam a ser denominados "Trilogia da Igualdade" (CEPAL, 2010, 2012a, 2014).

No contexto de recessão econômica internacional, era preciso encontrar meios para alcançar um "estilo de desenvolvimento" ${ }^{4}$ compatível com a

\footnotetext{
${ }^{4}$ De acordo com o enfoque cepalino, "estilo de desenvolvimento" é um conceito que busca entender a dinâmica das economias latino-americanas a partir das mudanças na relação entre as estruturas da oferta e da demanda (a estrutura da demanda é representada pela distribuição de renda e pelos padrões de consumo, enquanto a estrutura da oferta consiste nas composições setoriais do produto e do emprego).
} 
ampliação da proteção social e melhoria das condições de vida (CEPAL, 2012b). Ao contrário do ocorrido nos países desenvolvidos, onde as mudanças das estruturas produtivas vieram acompanhadas do desenvolvimento do Estado de bem-estar social, na América Latina as desigualdades eram (e ainda são) multidimensionais e a estrutura produtiva continuava fortemente heterogênea. A renda média dos países latino-americanos estava em ascensão, mas havia a necessidade de combater a desigualdade de uma forma integrada, em que se conjugassem melhorias nos mercados de trabalho e o aprimoramento dos programas de transferência de renda. Embora reconhecendo diferenças em termos de produtividade do trabalho e de graus de desenvolvimento dentro da região, o estudo revelou preocupação com a continuidade dos avanços obtidos até então. Frise-se que usou Portugal (cujo índice de Gini se reduziu de 0,388 em 2004 para 0,337 em 2009) como parâmetro para analisar a produtividade e o Produto Interno Bruto (PIB) per capita de diversos países latino-americanos (CEPAL, 2012b: 35). Ou seja, a CEPAL mostrou-se atenta aos avanços alcançados num cenário de geração de empregos e de expansão de políticas de transferência de renda, mas estimava que muito ainda estava por melhorar (comparando com Portugal, cujo PIB per capita havia crescido, entre 1972 e 2002, numa taxa média de 2,7\% ao ano). O estudo considerou o emprego como variável central da inclusão social e ponderou que era preciso aprimorar a estratégia de transformação produtiva para melhor qualificar os empregos criados. As preocupações externadas eram consoantes com o que ocorria no cenário macroeconômico da região.

Pouco depois, a CEPAL (2014) mostrou preocupação com o "futuro sustentável”, procurando compatibilizar o progresso econômico com a sustentabilidade ambiental. É discutida a distribuição da carga tributária e é reforçada a questão da heterogeneidade estrutural e seu impacto sobre o emprego. E é ressaltado que todas as formas de manifestação da desigualdade de renda devem ser analisadas - não apenas as rendas do trabalho, mas também as decorrentes de políticas de transferência condicionada e de pensões e aposentadorias, que podem amenizar ou reforçar a desigualdade econômica e social. O estudo inovou ao invocar a necessidade de entender a desigualdade de uma forma multidimensional, inclusive ao incorporar aspectos como a identidade étnica, o acesso a bens e serviços públicos, e problemas ambientais.

Em 2016 já eram visíveis os primeiros sinais de divergência da trajetória da desigualdade entre os países da região e o fato de as melhorias socioeconômicas estarem começando a se esvair (CEPAL, 2016). A agenda cepalina de desenvolvimento centrado na promoção da igualdade encontrou obstáculos econômicos, disputas políticas e resistências culturais. Desde 2015 
tem havido retrocessos sociais, especialmente no que se refere ao aumento da pobreza extrema. Apesar do cenário político hostil em vários países, ${ }^{5}$ a CEPAL (2018) continuou a defender a importância de reduzir a desigualdade para promover o desenvolvimento e consolidar a cidadania e a democracia. E passou a argumentar que a desigualdade gera ineficiência econômica, segregação territorial e deterioração ambiental.

Um dos fatores responsáveis pela redução da desigualdade na América Latina foi a duplicação do gasto social médio per capita, entre 2002 e 2016 (CEPAL, 2019). No entanto, em termos relativos, a magnitude do gasto social médio ainda se encontra muito abaixo do de países da OCDE, e a adoção de políticas de austeridade fiscal dificulta novos avanços. ${ }^{6}$ Note-se que os gastos relacionados a aposentadorias e pensões têm um peso importante para estratos inferiores de renda familiar nas respectivas pirâmides distributivas dos países, com efeito direto na redução da pobreza e da desigualdade.

A desindustrialização dos países da região também é um problema central, não só porque afeta o dinamismo e a qualidade do mercado de trabalho, como também deixa tais economias suscetíveis a oscilações dos preços internacionais das commodities. O período de prosperidade não foi suficiente para criar condições políticas e sociais favoráveis à consolidação de mudanças estruturais que pudessem sustentar ganhos expressivos de produtividade na América Latina (Ocampo et al., 2018).

Outro grave problema na região se refere à estrutura tributária fortemente regressiva (Amarante e Jiménez, 2016). O fortalecimento da democracia e de suas instituições revela-se um desafio importante se o objetivo é manter a trajetória de redução das desigualdades, uma vez que o Estado nacional possui diversas maneiras (além da política fiscal e tributária) de enfrentar o problema da desigualdade, como, por exemplo, a regulação da concorrência em mercados privados que produzem bens e serviços com peso importante nos orçamentos familiares. A definição do nível desses preços influencia o poder de compra dos salários (ibidem:52). Da mesma maneira, a expansão de serviços públicos nas áreas de saúde e educação tem um papel importante como mecanismo indireto de melhoria

\footnotetext{
${ }_{5}^{5}$ Por exemplo, houve quebra da ordem institucional e destituição do Chefe de Estado no Brasil (2016) e na Bolívia (2019). Em 2019, houve tumultos na Venezuela, no Chile, no Equador e no Peru. A democracia prevaleceu nas eleições presidenciais no México (2018) e na Argentina (2019). ${ }^{6}$ No caso do Brasil, isso foi tema de discussão no recente debate político sobre a "reforma" da Previdência Social: as transferências na forma de aposentadorias e de pensões (valores atrelados ao salário mínimo) tiveram, nos anos dos governos de Luiz Inácio Lula da Silva e de Dilma Rousseff, um papel importante na redução da pobreza.
} 
do perfil distributivo, pelos efeitos sobre os orçamentos familiares e/ou a qualidade de vida da população. ${ }^{7}$

Em suma, a agenda de desenvolvimento proposta pela CEPAL, baseada na mudança estrutural para a igualdade, busca a articulação de três tipos de eficiência: no nível microeconômico, no nível macroeconômico e na dimensão da sustentabilidade. A "eficiência schumpeteriana" coloca o foco na produtividade e nos processos de inovação tecnológica. A "eficiência keynesiana" se refere aos componentes que impulsionam o crescimento econômico (demandas doméstica e internacional), priorizando a redução do desemprego (e da subutilização da força de trabalho) e a elevação dos salários sem pressão inflacionária. A "eficiência ambiental" busca padrões de produção e consumo mais sustentáveis. E acrescente-se que as três eficiências são interdependentes e se reforçam simultaneamente (Chiliatto Leite, 2019). Ademais, trata-se de uma visão integrada do desenvolvimento, que requer a combinação de quatro tipos de políticas públicas: macroeconômica, industrial, social e ambiental. E no centro dessa agenda está o combate à desigualdade econômica e social.

\section{O caso do Brasil: a inflexão recente na trajetória da desigualdade}

Esta seção pretende fornecer breves explicações sobre os fatores que promoveram melhorias nos indicadores de mercado de trabalho e de distribuição de renda no Brasil, nos primeiros 15 anos do século XXI. ${ }^{8}$ São apresentados também dados referentes ao período entre 2015 e 2019, quando ocorreram, sucessivamente, uma reversão da atividade econômica, a crise política que levou ao impeachment da Presidente Dilma Rousseff' e a reforma trabalhista que retirou direitos aos trabalhadores. Desta forma, torna-se possível avaliar os efeitos da reversão do cenário econômico e do cenário político sobre a questão distributiva e sobre os indicadores de mercado de trabalho.

\footnotetext{
${ }^{7}$ Amarante e Jiménez (2016) destacam que não basta que a estrutura tributária seja progressiva, sendo necessário que a arrecadação seja significativa em termos de nível per capita, de tal forma que também o gasto efetivamente executado tenha efeito no enfrentamento das mazelas sociais da população.

${ }^{8}$ Para um entendimento do debate sobre as causas históricas da elevada concentração de renda no Brasil, ver Mattos (2017).

${ }^{9}$ Em 12 de maio de 2016, o Senado Federal confirmou a decisão da Câmara dos Deputados e aprovou o afastamento de Dilma Rousseff da Presidência da República, cargo para o qual ela havia sido eleita para exercer o mandato de 1 de janeiro de 2015 até 31 de dezembro de 2018. Na ocasião, a Presidência passou a ser exercida pelo Vice-presidente Michel Temer até a conclusão do mandato. O controverso processo, que contou com a articulação entre o Vice-presidente e políticos da oposição no Congresso Nacional, foi, por muitos, interpretado como um golpe contra o processo democrático que reelegera Dilma Rousseff em 2014 (Alves et al., 2017). Recentemente, um documentário sobre esse processo político (Democracia em vertigem, de Pedro Costa) foi indicado ao Oscar pela academia de Hollywood.
} 
Entre 2001 e 2014, a economia brasileira trilhou um caminho de redução da desigualdade econômica avaliada em sua dimensão da distribuição pessoal da renda, quer seja medida pelo índice de Gini (Gráfico 1$)^{10}$ quer por parcelas da renda total apropriadas pelos diferentes estratos populacionais da pirâmide distributiva. Os dados oficiais de pesquisas domiciliares revelaram uma tendência consistente, o que contrasta com o que ocorrera nas décadas anteriores, motivando uma expectativa otimista em relação à continuidade no processo de desconcentração dos rendimentos pessoais no Brasil.

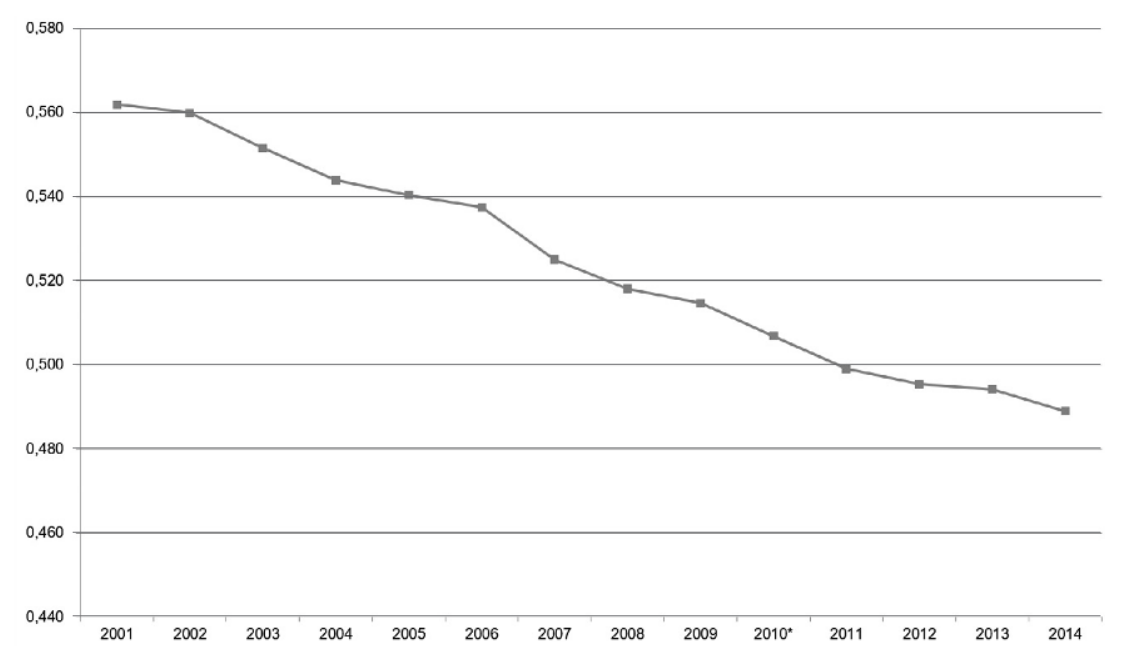

\section{GRÁFICO 1 - Índice de Gini dos rendimentos médios do trabalho (Brasil, 2001-2014)}

Fonte: Elaboração própria a partir de dados retirados do site do Instituto Brasileiro de Geografia e Estatística (IBGE), nomeadamente da Pesquisa Nacional por Amostra de Domicílios (PNAD).

Nota: * Para 2010 o índice foi estimado por interpolação linear, pois a PNAD não foi a campo em virtude da realização do Censo Demográfico.

A explicação para este desempenho deve ser buscada nos movimentos ocorridos no mercado de trabalho. Os principais indicadores do mercado de trabalho brasileiro, nos primeiros 15 anos do século XxI, revelam contínua formalização das relações de trabalho, revertendo duas décadas de redução da proporção de trabalhadores que se inseriam no espaço ocupacional sem acesso aos direitos trabalhistas, sociais e previdenciários.

${ }_{10}$ No Brasil, a Pesquisa Nacional por Amostra de Domićlios (PNAD) é a pesquisa domiciliar oficial sobre a realidade socioeconômica. Seus dados são obtidos pelo Instituto Brasileiro de Geografia e Estatística (IBGE). Em 2012, foi implantada uma nova pesquisa domiciliar, PNAD Contínua, com periodicidade trimestral. Ambas conviveram até 2015, quando o inquérito anual foi descontinuado, mantendo-se apenas o trimestral. 
Esta realidade andou junta com a ampliação dos rendimentos médios reais do trabalho e a redução de suas desigualdades atrás referida. É sempre importante pontuar que essa trajetória de criação de empregos formais deu-se com a legislação trabalhista vigente (revigorada e ampliada na Constituição Federal de 1988). ${ }^{11}$

A evolução do emprego, nas décadas de 1980 e de 1990, ainda sob esta mesma legislação, foi decepcionante devido ao baixo dinamismo da economia brasileira. Bastou que, nos anos 2000, a economia retomasse uma trajetória de crescimento econômico com expansão dos gastos de investimento e de consumo para que esse dinamismo se expressasse na geração de 1,3 milhão de postos de trabalho formais anuais, em média, no período entre 2000 e $2014 .^{12}$

Um elemento importante que ajuda a explicar o dinamismo desta geração de empregos está na demanda externa, extremamente estimulada para os produtos brasileiros, em especial a partir de 2004, por conta da expansão da atividade econômica na China (Araújo, 2021). O período entre 2004 e 2008 revelou crescimento do PIB, valorização cambial e inflação declinante. Em 2009, a economia sofreu os impactos da crise internacional, mas recuperou-se logo em seguida, atingindo a marca de $7,5 \%$ de crescimento anual do PIB já em 2010. A partir de 2011, porém, a economia passou a sofrer pronunciada desaceleração, devido não somente ao arrefecimento da demanda externa, como também à adoção de medidas macroeconômicas "prudenciais" pelo então novo governo de Dilma Rousseff, no sentido de reduzir os gastos públicos e controlar a expansão do crédito, por conta de pressões inflacionárias decorrentes da desvalorização cambial (Bruno, 2021). Entretanto, apesar da desaceleração do ritmo de criação de postos de trabalho, os resultados entre 2011 e 2013 ainda foram positivos, uma vez que medidas anteriormente adotadas nos governos de Lula da Silva foram mantidas pelo governo de Dilma Rousseff, como a recuperação do valor real do salário mínimo e as medidas de transferência de renda, de que é exemplo o Programa Bolsa Família, ${ }^{13}$ que teve uma importante expansão do número de famílias beneficiadas.

\footnotetext{
${ }^{11}$ Muitos direitos do trabalho foram "flexibilizados" em 2017, quando o Parlamento aprovou uma "reforma" trabalhista que tornou mais precárias as relações de trabalho e eliminou boa parte do conteúdo das normas que regulavam o padrão de emprego no Brasil. Em 2019 ocorreu nova rodada de flexibilização.

${ }_{12}$ Segundo dados do Cadastro Geral de Empregados e Desempregados do Ministério da Economia.

13 Principal política de combate à extrema pobreza por meio de transferência direta de dinheiro às famílias inscritas. Condicionalidades: manter filhos entre 6 e 17 anos a frequentar a escola; comparecer regularmente ao posto de saúde (principalmente mulheres gestantes ou amamentando); e vacinar as crianças.
} 
O período de dinamismo econômico, portanto, resultou de uma conjugação favorável de um cenário externo aquecido, acompanhado de medidas internas como a expansão do valor real do salário mínimo, o aumento do crédito e a instalação e posterior amplificação dos programas de transferência de renda - que tiveram tanto incremento de valores dos benefícios como também do número de famílias atendidas.

O primeiro mandato de Dilma Rousseff esteve eivado de contradições em relação ao controle inflacionário e ao estímulo ao crescimento econômico. Se, de um lado, ela e sua equipe mantiveram ou mesmo ampliaram políticas de inclusão social, por outro, as preocupações com o retorno da inflação levaram à implantação de medidas que amorteceram a demanda efetiva da economia. A redução de juros e a consequente desvalorização cambial, ocorridas entre setembro de 2011 e o início de 2013, não foram suficientes para redinamizar a economia (em especial as atividades industriais), fato que, ainda por cima, foi potencializado por um movimento de redução da demanda externa (desaceleração da economia chinesa). Outra estratégia, que posteriormente se revelou inócua e prejudicial, foi a concessão de isenções fiscais a diversos setores da atividade econômica, com o objetivo declarado de promover a redução de preços e a retomada de investimentos produtivos. Mas tais resultados não ocorreram, uma vez que os empresários se mostraram receosos de investir diante de um cenário de retração da atividade econômica.

Nesse cenário de desaceleração econômica, combinado com as isenções tributárias concedidas, o cenário fiscal se deteriorou, debilitando a arrecadação em todas as esferas da Federação brasileira. A desaceleração da economia já se materializara por meio da redução da taxa de investimento - inicialmente a pública e, logo a seguir, também a privada. Entre 2004 e 2010, o investimento total cresceu a uma taxa média real de cerca de $8 \%$ ao ano (acima do crescimento do PIB), mas no período 2011-2014 cresceu apenas a 1,8\% ao ano, conforme mostram Serrano e Summa (2015: 23). A produção industrial permaneceu, ainda em 2013, nos mesmos níveis de 2008 (ou seja, pré-crise), conforme menciona Bastos (2015).

O mercado de trabalho, desta forma, também começou a perder fôlego - embora com uma defasagem temporal em relação à perda de dinamismo das atividades dos diversos setores da economia. O cenário para o trabalho não era ainda desfavorável porque alguns mecanismos que haviam sido criados no período dos governos de Lula da Silva (como o aumento real do salário mínimo e a expansão do crédito) prosseguiam efetivos.

A retração dos investimentos e o fracasso das medidas de reanimação da atividade manufatureira promoveram a redução da taxa de crescimento da 
produtividade - acentuando um problema que estava a se manifestar desde o período em que o mercado de trabalho se aquecia - e alimentaram a desindustrialização, que acometeu e ainda tem acometido a economia brasileira. ${ }^{14}$

O processo político que culminou na deposição da Presidente Dilma Rousseff e na ascensão de Michel Temer ao comando do governo federal deflagrou uma sucessão de medidas neoliberais, que acarretaram a manutenção do cenário econômico de letargia e impactaram fortemente o mercado de trabalho. A reversão da trajetória de queda da desigualdade esteve associada aos sucessivos aumentos das taxas de desocupação e de subutilização da força de trabalho, ${ }^{15}$ e com a redução da proporção dos empregos formais (Gráfico 2).

A evolução destes indicadores mostra que as medidas de austeridade fiscal no início do segundo mandato de Dilma Rousseff e a própria crise política - que teve início ainda em 2015, com a abertura no Parlamento do processo de impeachment da Presidente - retroalimentaram a desaceleração econômica que se iniciara em meados de 2014 e conduziram a uma forte recessão. As incertezas advindas da ruptura política, bem como o engajamento de grande parte da classe empresarial brasileira $-{ }^{16}$ que apoiara o candidato derrotado no segundo turno da eleição de 2014 (o então Senador Aécio Neves) - paralisaram investimentos privados e trouxeram consequências deletérias à economia nacional. O PIB brasileiro registrou quedas anuais em torno de 3,5\% anuais no biênio 2015-2016 e tímido crescimento (média de 1,5\%) nos três anos seguintes. Entre 2015 e 2019, a queda acumulada foi de 2,5\%.

A combinação da austeridade econômica com a mudança na condução política, que inclusive resultou na "reforma trabalhista" de 2017 (pautada na flexibilização das relações de trabalho), trouxe reflexos desastrosos para o mercado de trabalho brasileiro. A influência de eventos políticos sobre a forte ampliação da taxa de desocupação pode ser notada na série trimestral (Gráfico 3). Houve também expressivo aumento da taxa de subutilização

\footnotetext{
${ }^{14}$ Ver entrevista com o economista Ha-Joon Chang, da Universidade de Cambridge realizada por Regiane Oliveira, em 2018. Cf. "'O Brasil está experimentando uma das maiores desindustrializações da história da economia'", El País Brasil, 15 de janeiro (consultada a 12.12.2019, em https://brasil. elpais.com/brasil/2018/01/05/economia/1515177346_780498.html).

${ }_{15}$ A taxa composta de subutilização da força de trabalho é a proporção da população subocupada por insuficiência de horas somada à população desocupada e à força de trabalho potencial, tendo como denominador a força de trabalho ampliada. Corresponde às pessoas que trabalham menos do que 40 horas semanais e gostariam de trabalhar mais horas, à população que busca trabalho e não o encontra e aos desalentados (aqueles que gostariam de trabalhar, mas desistiram de procurar efetivamente uma ocupação).

${ }^{16}$ Por exemplo, a Federação das Indústrias do Estado de São Paulo, maior entidade de classe da indústria brasileira, promoveu intensa campanha a favor do impeachment, inclusive com vasto espaço publicitário nas principais mídias do Brasil.
} 


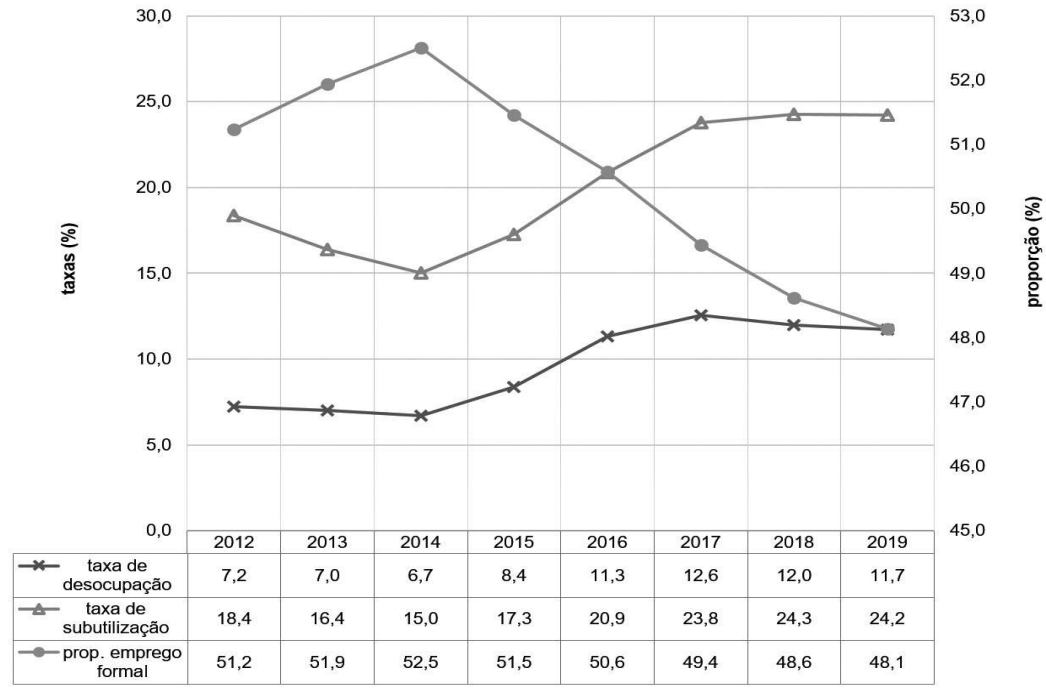

GRÁFICO 2 - Taxa de desocupação, taxa de subutilização e proporção de emprego formal (Brasil, 2012-2019)

Fonte: Elaboração própria a partir de dados retirados da PNAD Contínua no site do IBGE.

(\%)

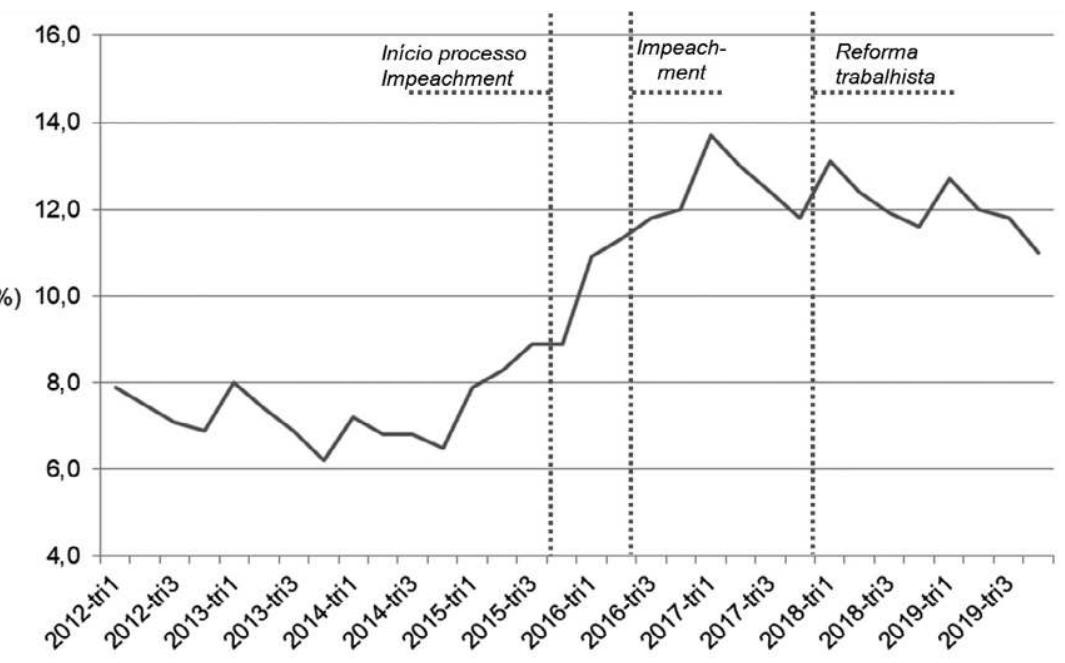

GRÁFICO 3 - Taxa de desocupação trimestral (Brasil, 2012-2019)

Fonte: Elaboração própria a partir de dados retirados da PNAD Contínua no site do IBGE. 
e da subocupação por insuficiência de horas trabalhadas, ${ }^{17}$ que embora em níveis já elevados, continuaram em crescimento após a reforma trabalhista. Esta trouxe mais precariedade às relações de emprego no Brasil, ao atender antigas demandas de segmentos empresariais.

Embora a deterioração do mercado de trabalho tenha sido generalizada entre 2015 e 2016 (e não tenha sido revertida posteriormente), ainda assim, graças à legislação de reajustes anuais reais para o salário mínimo, os rendimentos médios dos ocupados foram menos afetados. Cabe ponderar, no entanto, que a preservação da média dos rendimentos também pode ser atribuída ao aumento da desocupação, uma vez que os trabalhadores que perderam seu posto de trabalho e ficaram com renda do trabalho nula são, por definição, excluídos do denominador (número de ocupados). Mas, a massa de rendimentos do trabalho diminuiu por causa da recessão econômica, acompanhando a queda do PIB real. Ao se considerar toda a força de trabalho no denominador, o rendimento médio por trabalhador indicou redução expressiva entre 2015 e 2017 e leve recuperação nos dois anos seguintes (Gráfico 4). Embora para os que se mantiveram no mercado de trabalho os rendimentos reais médios mensais não tenham sofrido forte redução, para o conjunto dos trabalhadores brasileiros verificou-se uma perda real da renda média do trabalho, que passou de R $\$ 2200$ para $\mathrm{R} \$ 2039$ entre 2014 e 2019 (ou seja, uma redução de $7,3 \%$ ).

Apesar da deterioração do mercado de trabalho a partir de 2015, o crescimento da desigualdade funcional da renda se manifestou apenas em 2017, ou seja, quando a economia brasileira saiu da recessão e iniciou uma recuperação débil. A participação dos rendimentos do trabalho na renda nacional, que registrava trajetória ascendente, mostrou sinal de retração ao fim do período (Gráfico 5). Entre 2004 e 2015, a massa de rendimentos havia crescido num ritmo superior ao de crescimento do PIB, mas essa tendência foi interrompida e revertida a partir de 2016.

A distribuição funcional da renda apresenta duas tendências consolidadas na série histórica. De 1995 a 2004, os salários e outros rendimentos do trabalho perderam continuamente participação, enquanto de 2004 a 2015 ocorreu o inverso. Em 2016, ano da deposição da Presidente Dilma, a curva da participação no PIB das remunerações dos trabalhadores começa a infletir e passa a indicar queda. ${ }^{18}$

\footnotetext{
17 A taxa de subutilização passou de 15,8\% em 2014 para 24,2\% em 2018 e a taxa de subocupação cresceu de 5,4\% para 7,5\%, em igual período (dados retirados da PNAD Contínua, disponível no site do IBGE).

18 Até ao momento da redação deste artigo, o último ano disponível na série de participação das remunerações de trabalho sobre o PIB era 2018 (dados do Sistema de Contas Nacionais, IBGE).
} 


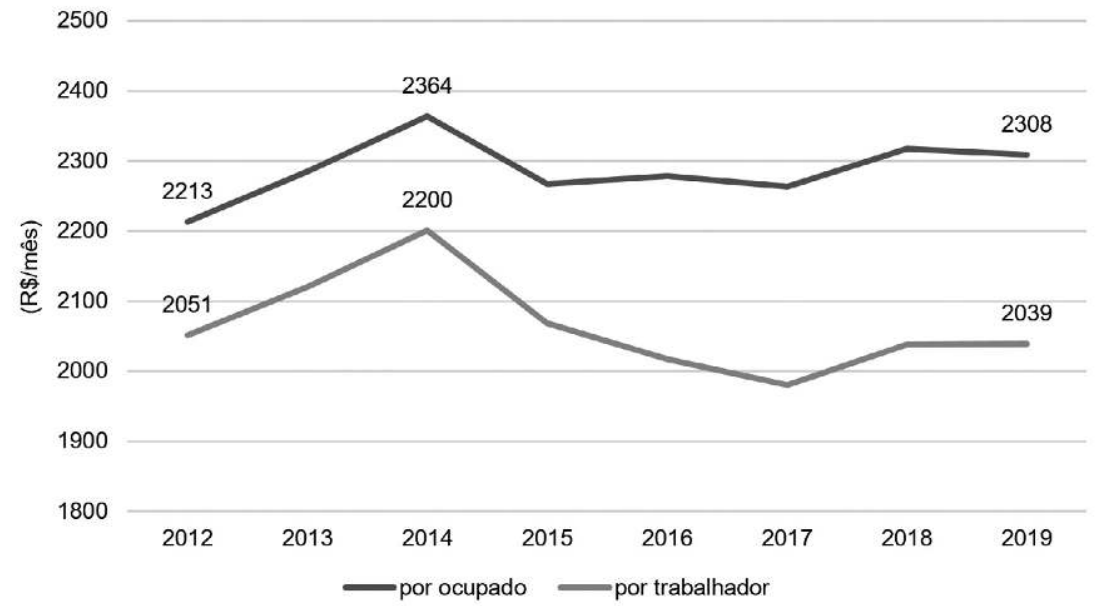

GRÁFICO 4 - Rendimento médio real anual por grupo populacional (Brasil, 2012-2019)

Fonte: Elaboração própria a partir de dados retirados da PNAD Contínua no site do IBGE.

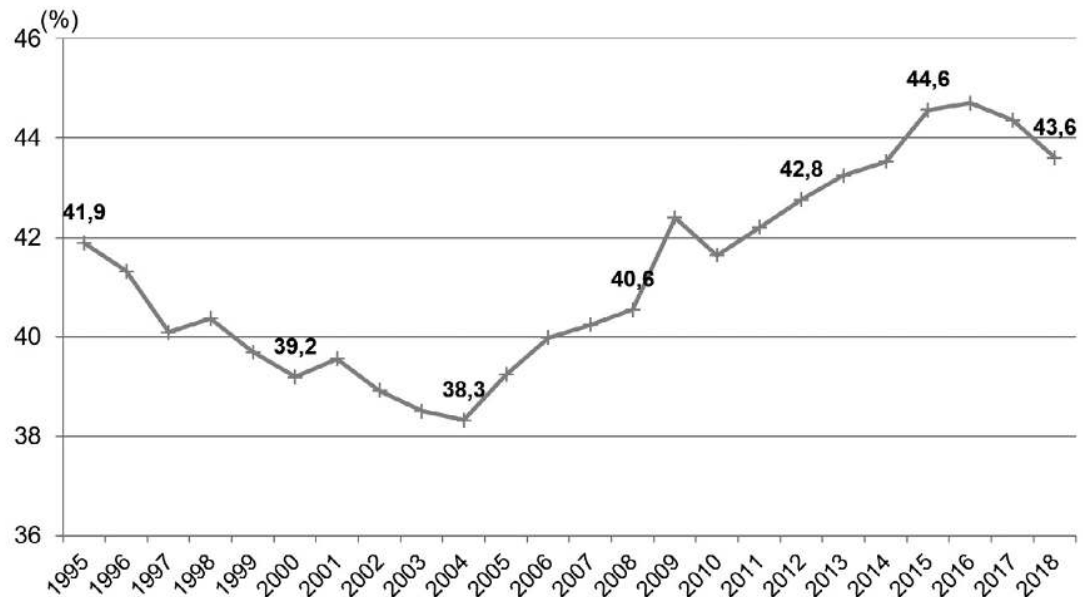

GRÁFICO 5 - Participação das remunerações do trabalho no PIB (Brasil, 1995-2018)

Fonte: Elaboração própria a partir de dados retirados do Sistema de Contas Nacionais no site do IBGE. 
Num período de dez anos, entre 1995 e 2004, o país registrou baixo crescimento econômico, resultado que se refletiu também nas opções macroeconômicas restritivas adotadas por conta da vulnerabilidade externa da economia brasileira frente às crises observadas em países emergentes. ${ }^{19}$ Tal conjuntura impactou severamente o mercado de trabalho brasileiro, que registrou aumento do desemprego e da informalidade, bem como achatamento dos salários, fenómenos que voltaram a marcar os tempos atuais.

A retomada do crescimento de forma robusta e a consequente recuperação do emprego e das remunerações na renda nacional vieram a ocorrer a partir de 2004 e forjaram a segunda tendência, a da recuperação da participação das remunerações, que prosseguiu até 2015 , embora o crescimento do PIB tenha oscilado nos anos finais deste subperíodo. De 2004 a 2008, pela primeira vez na economia brasileira desde 1980, ocorreram cinco anos consecutivos de elevação do PIB acima de 3\% ao ano. ${ }^{20}$ De 2004 a 2014 houve também ampliação do nível de ocupação, aumento da formalização e substanciais crescimentos na remuneração do trabalho. Como mencionado, o salário mínimo nacional, variável fundamental para a determinação de grande parte das remunerações no país, recebeu contínuos reajustes acima da inflação nesse mesmo período. ${ }^{21}$

Sob a perspectiva da distribuição pessoal da renda, nota-se que após 2014 a trajetória em prol de redução das desigualdades começou a retroceder, como mostra o índice de Gini, de acordo com a nova pesquisa amostral realizada pelo IBGE iniciada em 2012 (Gráfico 6).

A desigualdade dos rendimentos - medida tanto para a renda média individual do trabalho quanto para a renda total domiciliar per capita - apresentou tendência de diminuição até 2015 e crescimento nos anos seguintes, confirmando que a reversão da trajetória de queda da desigualdade foi uma das consequências da adoção de políticas e reformas de caráter neoliberal no Brasil.

\section{Uma utopia interditada}

A agenda nacional de desenvolvimento formulada pela CEPAL para cada país da América Latina, centrada no combate às desigualdades econômicas,

\footnotetext{
${ }_{19}$ Desde meados da década de 1990, alguns países, especialmente aqueles considerados emergentes, experimentaram crises cambiais e financeiras: México (1994), Coreia do Sul, Indonésia e Tailândia (1997), Rússia (1998), Brasil (1999) e Argentina (2001).

${ }^{20}$ De 2004 a 2008, o crescimento médio anual do PIB foi equivalente a 4,8\%. Incluindo-se o recessivo ano de 2009 , a média recuou para $4 \%$, taxa ainda elevada para o padrão brasileiro recente. ${ }^{21}$ Saboia e Hallak Neto (2018) estimaram em aproximadamente $60 \%$ a influência dos reajustes do salário mínimo sobre a massa de remunerações.
} 
foi qualificada por Cordera Campos (2014) como uma "utopia realista", isto é, uma agenda viável para uma transformação profunda dessas sociedades. Nesse enfoque otimista, o Estado nacional deve implementar uma estratégia que mantenha o pleno emprego, estimule o crescimento da produtividade do trabalho, corrija as distorções da estrutura tributária e oferte políticas sociais universais (indo além de programas focados na extrema pobreza) para promover o desenvolvimento inclusivo. Em adição, também deve atuar na preservação do meio ambiente.

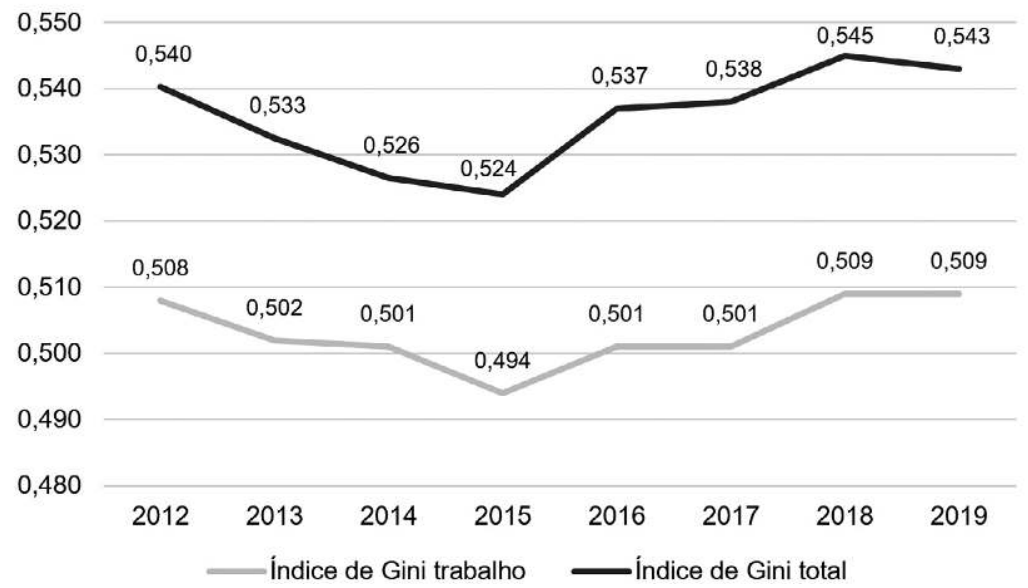

\section{GRÁFICO 6 - Índice de Gini do rendimento do trabalho e do rendimento domiciliar per capita (Brasil, 2012-2019)}

Fonte: Elaboração própria a partir de dados retirados da PNAD Contínua no site do IBGE.

A partir de 2015, houve mudanças estruturais e institucionais nos países latino-americanos, que tornaram mais difícil a formulação ou manutenção de uma estratégia desse tipo. Em algumas dessas sociedades nota-se atualmente um descompromisso com políticas e reformas que poderiam reduzir as desigualdades econômicas. A frustração de amplos segmentos sociais em alguns países onde a pobreza e a desigualdade haviam caído de modo significativo - tais como Argentina, Bolívia, Brasil, Chile e Venezuela - provocou manifestações de protesto, que em alguns casos desembocaram em embates políticos violentos, denotando um acirramento da luta de classes.

No rol das questões em disputa, merece destaque a dificuldade para promover mudanças significativas na estrutura tributária (Lustig et al., 2014), que continua marcada por elevada regressividade. É uma característica institucional que afeta, no limite, a própria consolidação da democracia 
no continente. A situação certamente é mais grave em países onde a cultura de privilégios é mais arraigada e as classes dominantes não sabem conviver com a ascensão social de grupos étnicos (que, historicamente, estiveram apartados dos frutos do progresso material) ou de setores organizados da classe trabalhadora.

Enquanto o crescimento econômico foi duradouro e robusto, como se verificou no Brasil entre 2004 e 2014, a inclusão social se tornou viável, principalmente por meio da geração de empregos e da elevação dos salários, mas também por meio de políticas sociais (mesmo em países onde os programas de transferência de renda foram muito tímidos e os mecanismos de compartilhamento dos ganhos sistêmicos de produtividade foram muito limitados). Mas, quando eclodiu a crise econômica, as demandas sobre o Estado se ampliaram, explicitando os divergentes interesses em conflito. Nesse contexto desfavorável, ficou nítido que as elites latino-americanas assumem posição contrária à agenda de desenvolvimento da CEPAL.

O processo jurídico-parlamentar que resultou no impeachment da Presidente Dilma significou, na prática, um golpe contra instituições democráticas e contra direitos sociais inscritos na Constituição Federal de 1988. É possível afirmar que foi um ataque contra os interesses de amplos setores da classe trabalhadora e em favor de frações da classe dominante.

Se é verdade que, no início da década de 2010, o Brasil estava a caminhar na direção de maior "justiça social", 22 a ruptura política representou a interdição de um projeto de reconstrução da nação. A crise de governabilidade aprofundou a crise econômica, com efeitos nocivos sobre o mercado de trabalho. Após a deposição da Presidente, o Parlamento aprovou um "teto para os gastos sociais" do governo federal, seguida de uma "reforma trabalhista" e na sequência de uma "reforma da Previdência", que de fato promoveram a redução de direitos sociais e trabalhistas e a precarização dos empregos formais, conforme mostrado na segunda seção deste artigo.

O governo eleito no final de 2018 levou ao poder uma coalizão política que tem, sistematicamente, provocado o desmonte de instituições públicas

\footnotetext{
${ }^{22}$ Para Wright (2010), a construção de uma democracia igualitária deve se assentar em dois postulados normativos, um relativo às condições da "justiça social" e o outro à "justiça política". Interessa aqui destacar o conceito de "justiça social", que envolve três aspectos: prosperidade humana, crescimento material e social necessários para esta prosperidade, e acesso igualitário às oportunidades. É condição para a "justiça política", que abrange o empoderamento democrático coletivo e supõe que as pessoas possam participar das decisões políticas que afetam seu destino. Portanto, é fundamental pensar na ideia de igualdade em um sentido mais amplo do que a dimensão econômica. Ademais, Wright (2019) afirma que a ideia de igualdade é central para todas as noções de justiça social, e que os níveis de desigualdade existentes nas economias capitalistas, tanto na renda quanto na riqueza, violam os princípios igualitários de justiça social.
} 
que promoviam redistribuição da renda (por exemplo, cortando gastos com educação superior, serviços de saúde e assistência social). Trata-se de um ataque orquestrado contra os setores sociais mais progressistas, ataque que não se restringe a denunciar os direitos sociais como produto de uma visão irrealista a respeito das capacidades do Estado e que passa a responsabilizá- los pela adoção de políticas populistas causadoras de desequilíbrios no Orçamento da União (PMDB, 2015; Grupo Banco Mundial, 2017).

A partir de 2017, as reformas neoliberais aprovadas pelo Parlamento e as medidas tomadas pelo governo federal, além de piorarem as relações de trabalho e a qualidade dos postos de trabalho criados, iniciaram o desmonte de mecanismos institucionais que permitiam aos cidadãos exercer maior participação na sociedade civil e agir sobre seus destinos como atores sociais.

Foram desmontados dezenas de conselhos e aparatos estatais ou da sociedade civil que, de alguma forma, ainda de maneira muito embrionária, na ainda frágil democracia brasileira, compunham elementos de um projeto de transformação social. Basta lembrar que, já no quarto mês de seu mandato, o atual Presidente da República, Jair Bolsonaro, promoveu a extinção de conselhos relacionados a temas cruciais, ${ }^{23}$ como a defesa do meio ambiente, as cotas para pessoas com deficiência, os direitos de pessoas da comunidade LGBT, a promoção da diversidade cultural, o direito ao uso do solo urbano, a defesa de igualdades étnico-raciais, o regramento da educação pública, entre outros. Estes são temas importantes para assegurar o exercício da cidadania e, precisamente por isso, vêm sendo atacados pelas forças políticas de extrema direita.

O estreitamento da participação popular e o enfraquecimento dos sindicatos, num contexto de deterioração do mercado de trabalho e aumento da concentração de renda, não foram vistos com preocupação pelos grandes meios de comunicação, o que revela o predomínio de um discurso conservador na sociedade brasileira, hostil a quaisquer iniciativas que possam construir pontes para uma "utopia realista".

Economistas heterodoxos continuaram se inspirando no enfoque cepalino para propor um projeto de desenvolvimento sustentável para o Brasil (Chiliatto Leite, 2019). Não obstante, sabe-se que os desafios são imensos, seja porque a conjuntura econômica externa não mais se encontra tão favorável quanto no início da década de 2000, seja porque foram enfraquecidos dois motores endógenos do crescimento inclusivo: a distribuição

${ }^{23}$ Consultar FETAMCE (2019), "Decreto de Bolsonaro extingue pelo menos 35 conselhos sociais”, 12 de abril (consultado a 15.12.2019, em http://fetamce.org.br/decreto-de-bolsonaroextingue-pelo-menos-35-conselhos-sociais/). 
de renda (via mercado de trabalho e tributação progressiva) e o investimento público nas políticas sociais (Dweck e Rossi, 2019).

Sem dúvida, as elites mais poderosas no Brasil responderam à crise econômica com nítido endurecimento da luta de classes e tentaram controlar todas as instâncias de poder. Mas a eleição de um político ultradireitista para a Presidência da República tem causado uma série de tensões sociais, que desestabilizam a vida política nacional, e há dúvidas sobre a possibilidade de solucionar os impasses atuais com os instrumentos democráticos disponíveis, em particular via processo eleitoral. Fica registrado o desafio de entender como as classes sociais e suas diferentes frações de classe agem diante de um cenário de demonização da política, crise institucional e estagnação econômica, que levou parcela significativa da população a sufragar em favor de seus algozes.

\section{Considerações finais}

O golpe jurídico-parlamentar de 2016 que instaurou um governo neoliberal no Brasil foi seguido por uma conspiração de forças conservadoras, as quais têm procurado sepultar o sonho de uma nação menos desigual. Não há dúvida de que foi invalidado o processo de inclusão social. As medidas que reduziram direitos trabalhistas e previdenciários e as restrições aos gastos com políticas sociais foram apresentadas como inevitáveis diante do endividamento público crescente - sem que se colocasse em pauta a possibilidade de combate ao rentismo que viciou a classe dominante.

A agenda de desenvolvimento inclusivo proposta pela CEPAL, que vai além da redução da desigualdade de renda, foi abortada precocemente. O discurso cepalino contemporâneo, ao se renovar, ficou preso ao paradoxo de tentar ser, ao mesmo tempo, "utópico" e "realista", inclusive quando busca contemplar a preocupação com o meio ambiente e com a participação política de grupos sociais que sempre foram discriminados negativamente no Brasil e em outros países da América Latina. Fica evidente, também, que para se tornar legítima e viável, a agenda da CEPAL necessita de um ambiente político democrático e de uma profunda mudança cultural.

Para finalizar, convém mencionar que a crise econômica produzida pela pandemia da COVID-19 em 2020 causou forte deterioração nos mercados de trabalho latino-americanos e aumentou o número de pessoas e famílias em situação de pobreza e vulnerabilidade social. Contudo, ainda é cedo para uma análise dos impactos da crise ainda em curso sobre a questão social e a distribuição de renda no Brasil.

Revisto por Ana Sofia Veloso 


\section{Referências bibliográficas}

Amarante, Verónica; Jiménez, Juan Pablo (2016), “Distribución del ingreso e imposición a las altas rentas en América Latina”, Cuadernos de Economía, 35 (67), 39-73. Consultado a 19.12.2019, em https://www.redalyc.org/pdf/2821/282142131003.pdf.

Alves, Giovanni; Gonçalves, Mirian; Tonelli, Maria Luiza Quaresma; Ramos Filho, Wilson (coords.) (2017), Enciclopédia do golpe - Vol. I. Bauru: Canal 6 Editora/Projeto Editorial Praxis. Consultado a 16.12.2019, em http://biblioteca.clacso.edu.ar/clacso/ se/20181026043346/Enciclopedia_vol_1.pdf.

Araújo, Victor Leonardo (2021), “O primeiro Governo Lula (2003-2006): retomada do crescimento e bonança internacional”, in Victor Leonardo de Araújo; Fernando Augusto Mansor de Mattos (orgs.), A economia brasileira de Getúlio a Dilma: novas interpretações. São Paulo: Hucitec, 469-490.

Bastos, Pedro Paulo Zahluth (2015), "Austeridade para quem? A crise global do capitalismo neoliberal e as alternativas no Brasil", Texto para Discussão - Unicamp, 257. Consultado a 15.12.2019, em http://www.eco.unicamp.br/images/arquivos/artigos/3410/TD257.pdf.

Bértola, Luis; Ocampo, José Antonio (2015), O desenvolvimento econômico da América Latina desde a independência. Rio de Janeiro: Elsevier Editora.

Bértola, Luis; Castelnovo, Cecilia; Rodríguez, Javier; Willebald, Henry (2009), "Income Distribution in the Latin American Southern Cone During the First Globalization Boom and Beyond", International Journal of Comparative Sociology, 50(5-6), 452-485. DOI: 10.1177/0020715209339883

Bourguignon, François; Morrisson, Christian (2002), "Inequality among World Citizens: 1820-1992”, American Economic Review, 92(4), 727-744. DOI: 10.1257/0002828 0260344443

Bruno, Miguel (2021), "Os governos Dilma Rousseff: da 'nova matriz macroeconômica' ao golpe de 2016”, in Victor Leonardo de Araújo; Fernando Augusto Mansor de Mattos (orgs.), A economia brasileira de Getúlio a Dilma: novas interpretações. São Paulo: Hucitec, 517-536.

CEPAL (2010), "A hora da igualdade: brechas por selar, caminhos por abrir - Síntese”. Santiago: Nações Unidas, Comissão Econômica para a América Latina e o Caribe. Consultado a 10.11.2019, em https://www.cepal.org/pt-br/publicaciones/3156-horaigualdade-brechas-selar-caminhos-abrir-trigesimo-terceiro-periodo-sessoes.

CEPAL (2012a), "Mudança estrutural para a igualdade: uma visão integrada do desenvolvimento - Síntese”. Santiago: Nações Unidas, Comissão Econômica para a América Latina e o Caribe. Consultado a 10.11.2019, em https://www.cepal.org/pt-br/ publicaciones/13948-mudanca-estrutural-igualdade-visao-integrada-desenvolvimentotrigesimo-quarto.

CEPAL (2012b), Eslabones de la desigualdad: heterogeneidad estructural, empleo y protección social. Santiago de Chile: Naciones Unidas, Comisión Económica para 
América Latina y el Caribe. Consultado a 10.11.2019, em https://www.cepal.org/es/ publicaciones/27973-eslabones-la-desigualdad-heterogeneidad-estructural-empleoproteccion-social.

CEPAL (2014), "Pactos para a igualdade: rumo a um futuro sustentável - Síntese". Santiago: Nações Unidas, Comissão Econômica para a América Latina e o Caribe. Consultado a 10.11.2019, em https://www.cepal.org/pt-br/publicaciones/40013pactos-igualdade-rumo-futuro-sustentavel-sintese.

CEPAL (2016), Horizontes 2030: a igualdade no centro do desenvolvimento sustentável. Santiago: Nações Unidas, Comissão Econômica para a América Latina e o Caribe. Consultado a 11.11.2019, em https://www.cepal.org/pt-br/publicaciones/40161-horizontes2030-igualdade-centro-desenvolvimento-sustentavel.

CEPAL (2018), “A ineficiência da desigualdade - Síntese”. Santiago: Nações Unidas, Comissão Econômica para a América Latina e o Caribe. Consultado a 11.11.2019, em https://www.cepal.org/pt-br/publicaciones/43569-ineficiencia-desigualdadesintese.

CEPAL (2019), Panorama social da América Latina - 2018. Santiago: Nações Unidas, Comissão Econômica para a América Latina e o Caribe. Consultado a 12.11.2019, em https://www.cepal.org/pt-br/publicaciones/44412-panorama-social-americalatina-2018-documento-informativo.

CEPAL (2021), Panorama social de América Latina 2020. Santiago: Naciones Unidas, Comisión Económica para América Latina y el Caribe. Consultado a 10.03.2021, em https://www.cepal.org/es/publicaciones/46687-panorama-social-america-latina-2020.

Chiliatto Leite, Marcos Vinicius (org.) (2019), "Novos horizontes para o desenvolvimento com igualdade no Brasil: desafios em um mundo em transformação", in Alternativas para o desenvolvimento brasileiro: novos horizontes para a mudança estrutural com igualdade. Santiago: Nações Unidas, Comissão Econômica para a América Latina e o Caribe, 11-31. Consultado a 30.11.2019, em https://www.cepal.org/pt-br/ publicaciones/44616-alternativas-o-desenvolvimento-brasileiro-novos-horizontesmudanca-estrutural.

Cordera Campos, Rolando (2014), "El desarrollo ayer y hoy: idea y utopía”, Revista CEPAL, 113, 7-21. Consultado a 30.10.2020, em https://www.cepal.org/es/ publicaciones/36955-desarrollo-ayer-hoy-idea-utopia.

Dedecca, Claudio Salvadori (2012), “Desigualdade, mas de qual falamos?”, Revista de Economia Política, 32(1), 55-71. Consultado a 21.10.2020, em https://www.scielo.br/ $\mathrm{pdf} / \mathrm{rep} / \mathrm{v} 32 \mathrm{n} 1 / 04 . \mathrm{pdf}$.

Dweck, Esther; Rossi, Pedro (2019), "Políticas sociais, distribuição, crescimento e mudança estrutural”, in Marcos Vinicius Chiliatto Leite (org.), Alternativas para o desenvolvimento brasileiro: novos horizontes para a mudança estrutural com igualdade. Santiago: Nações Unidas, Comissão Econômica para a América Latina e o Caribe, 97-116. Consultado 
a 30.11.2019, em https://www.cepal.org/pt-br/publicaciones/44616-alternativas-odesenvolvimento-brasileiro-novos-horizontes-mudanca-estrutural.

Frankema, Ewout (2009), Has Latin America always Been Unequal? A Comparative Study of Asset and Income Inequality in the Long Twentieth Century. Leiden: Brill.

Gasparini, Leonardo (2006), "La distribución del ingreso: un breve resumen de tres décadas”, Econômica, 52(1-2), 53-76. Consultado a 29.11.2019, em https://revistas. unlp.edu.ar/Economica/article/view/5503.

Grupo Banco Mundial (2017), "Um ajuste justo. Análise da eficiência e equidade do gasto público no Brasil. Volume I: síntese”. Washington, D.C.: World Bank Group. Consultado a 28.11.2019, em https://www.worldbank.org/pt/country/brazil/ publication/brazil-expenditure-review-report.

Lustig, Nora; Pessino, Carola; Scott, John (2014), “The Impact of Taxes and Social Spending on Inequality and Poverty in Argentina, Bolivia, Brazil, Mexico, Peru, and Uruguay: Introduction to the Special Issue”, Public Finance Review, 42(3), 287-303. DOI: $10.1177 / 1091142113506931$

Mattos, Fernando Augusto Mansor de (2017), "O debate sobre distribuição de renda ao longo do processo de desenvolvimento econômico no Brasil", Revista da ABET, 16(1), 160-189. DOI: 10.22478/ufpb.1676-4439.2017v16n1.36040

Mello, Luis de; Dutz, Mark A. (orgs.) (2012), Promoting Inclusive Growth: Challenges and Policies. Paris: OECD/World Bank. Consultado a 28.11.2019, em https://open knowledge.worldbank.org/handle/10986/16948.

Ocampo, José Antonio; Bastian, Eduardo F.; Reis, Marcos (2018), "The Myth of the 'Latin American Decade'”, PSL Quarterly Review, 71(285), 231-251. Consultado a 28.11.2019, em https://ojs.uniroma1.it/index.php/PSLQuarterlyReview/article/view/14354.

PMDB - Partido do Movimento Democrático Brasileiro (2015), "Uma ponte para o futuro”. Brasília: Fundação Ulysses Guimarães. Consultado a 15.11.2016, em https:// www.fundacaoulysses.org.br/wp-content/uploads/2016/11/UMA-PONTE-PARAO-FUTURO.pdf.

Saboia, João; Hallak Neto, João (2018), "Salário mínimo e distribuição de renda no Brasil a partir dos anos 2000", Economia e Sociedade, 27(1), 265-285. DOI: 10.1590/1982-3533.2017v27n1art9

Serrano, Franklin; Summa, Ricardo (2015), “Aggregate Demand and the Slowdown of Brazilian Economic Growth from 2011-2014”. Washington, D.C.: Center for Economic and Policy Research. Consultado a 23.09.2018, em https://cepr.net/documents/ Brazil-2015-08.pdf.

Sokoloff, Kenneth; Robinson, James (2004), "Historical Roots of Inequality in Latin America”, in David de Ferranti; Guillermo E. Perry; Francisco H. G. Ferreira; Michael Walton (orgs.), Inequality in Latin America: Breaking with History? Washington, D.C.: The World Bank, 109-122. Consultado a 13.11.2019, em https://openknowledge. worldbank.org/handle/10986/15009. 
The World Bank (2016), Poverty and Shared Prosperity 2016: Taking on Inequality.

Washington, D.C.: World Bank Group. Consultado a 28.11.2019, em https://www. worldbank.org/en/publication/poverty-and-shared-prosperity-2016.

Wright, Erik Olin (2010), Envisioning Real Utopias. London: Verso.

Wright, Erik Olin (2011), "Utopias reais para uma sociologia global”, Diálogo Global, 1(5), 3-4. Consultado a 20.01.2020, em https://globaldialogue.isa-sociology.org/ wp-content/uploads/2013/07/v1i5-portuguese.pdf.

Wright, Erik Olin (2019), Como ser anticapitalista no século XXI? São Paulo: Boitempo. Tradução de Fernando Cauduro Pureza.

Artigo recebido a 16.11.2020

Aprovado para publicação a 18.03.2021

\section{Fernando Augusto Mansor de Mattos}

Faculdade de Economia, Universidade Federal Fluminense

Rua Professor Marcos Waldemar de Freitas Reis, s/n, Campus do Gragoatá, Bloco F, CEP 24210-201

Niterói, Rio de Janeiro, Brasil

Contacto: fermatt1@hotmail.com

ORCID: https://orcid.org/0000-0002-1196-3246

\section{João Hallak Neto}

Instituto Brasileiro de Geografia e Estatística

Av. República do Chile, 500, 8. ${ }^{\circ}$ andar, CEP 20031-170 Centro, Rio de Janeiro, Brasil

Contacto: joao.hallak@gmail.com

ORCID: https://orcid.org/0000-0001-7302-2073

\section{Marcelo Weishaupt Proni}

Instituto de Economia, Universidade Estadual de Campinas

Rua Pitágoras, 353, Barão Geraldo, CEP 13083-857 Campinas, São Paulo, Brasil

Contacto: mwproni@unicamp.br

ORCID: https://orcid.org/0000-0003-2096-7553 


\section{ECLAC's Utopian Vision and Income Inequality in Brazil}

In 2014, Economic Commission for Latin America and the Caribbean (ECLAC) stated that a development strategy aimed at greater economic equity, greater social justice and greater environmental protection could be adopted in several countries in Latin America - a scenario which however has been disfigured in recent years. This article thus has three objectives: (1) to analyze the utopian character of ECLAC's agenda for the promotion of more egalitarian societies in Latin America; (2) to list the main determinants of the reduction of income inequality in Brazil in the period 2004-2014; and (3) to examine the interruption of the trajectory of reduction of income inequality - from the 2016 political coup and the approval of neoliberal reforms that increased the precariousness of jobs and weakened the social protection system -, as evidence of the interdiction of an inclusive development strategy in Brazil. Keywords: Brazil; ECLAC; labour inequalities; labour market; Latin America.

\section{La vision utopique de la CEPALC et l'inégalité des revenus au Brésil}

En 2014, la Commission économique pour l'Amérique latine et les Caraibes (CEPALC) a déclaré qu'une stratégie de développement visant à une plus grande équité économique, une plus grande justice sociale et une plus grande protection de l'environnement pourrait être adoptée dans plusieurs pays d'Amérique latine - un scénario qui s'est toutefois défiguré ces dernières années. Cet article a donc trois objectifs : (1) analyser la nature utopique de l'agenda de la CEPALC pour la promotion de sociétés plus égalitaires en Amérique latine ; (2) énumérer les principaux déterminants de la réduction des inégalités de revenus au Brésil au cours de la période 2004-2014 ; et (3) examiner l'interruption de la trajectoire de réduction des inégalités de revenus - depuis le coup d'État politique de 2016 et l'approbation de réformes néolibérales qui ont accru la précarité de l'emploi et affaibli le système de protection sociale - comme preuve de l'interdiction d'une stratégie de développement inclusif au Brésil.

Mots-clés: Amérique latine; Brésil; CEPALC; inégalités au travail; marché du travail. 
